\title{
PROCEEDINGS OF THE CAMBRIDGE ENTOMOLIGAL CLUB.
}

Ten meetings were held in 1928, including one special meeting in September. The programs were as follows: Jan. 10 : Dr. O. E. Plath, "Bumblebees, their Life History, Habits and Economic Importance." Feb. 13: Professor J. C. Bradley, "Scoliidae, with Particular Reference to the Development of Antigeny of Some Species." March 13: Dr. George Salt, "A Year in Colombia, South America." April 10, Mr. J. H. Emerton, "Notes on Spiders Collected in 1927"; and Mr. A. P. Morse, C. W. Johnson, and C. A. Frost, "The Distribution of Insects in New England." May 8, Mr. S. M. Dohanian, "Eighteen Months in Europe." June 12, Dr. J. Bequeart, "Vespidæ of the West Indies." September 11, Summer collecting notes. October 9, Mr. W. J. Clench, "Collecting Experiences in Cuba." November 13, Dr. George Salt, "Strepsiptera." December 11, Dr. F. M. Carpenter, "The Fossil Ants of North America."

Eleven new members were elected during 1928, bringing the total membership to ninety-one.

J. W. WiLson, Secretary.

\section{THE UNEXPECTED ACID TEST.}

While wandering along the banks of the Shawsheen River in Andover, Mass., one pleasant spring day I found a specimen of Carabus vinctus Web. under a piece of board. I at one pounced upon it as a prize, for at that time I had taken but few of them, and brought it closer to my face for another gloating look. As I did so I experienced the sensation that might have been caused by half a dozen red-hot needles striking my face, and at once lost all interest in the beetle until I had wiped my face with alcohol and stopped the painful smarting. I then investigated and came to the conclusion that the pressure of my thumb and finger had caused the apices of the elytra to impinge one against the other and, acting like a released spring, threw the acid secretion from the beetle into the air eight inches or more. I was greatly surprised at the strength of this acid and would fear rather severe results if it should enter the eyes.

C. A. Frost. 

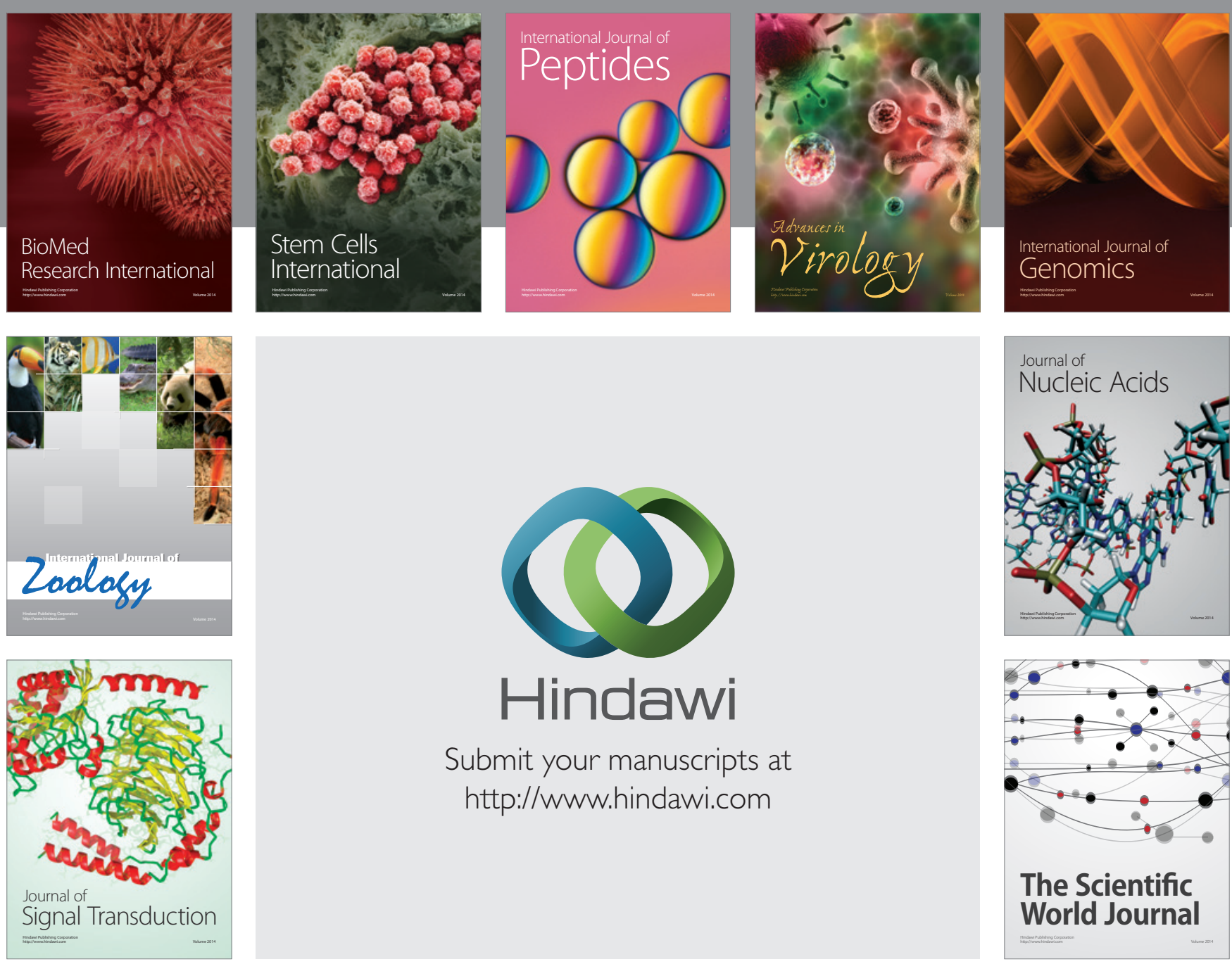

Submit your manuscripts at

http://www.hindawi.com
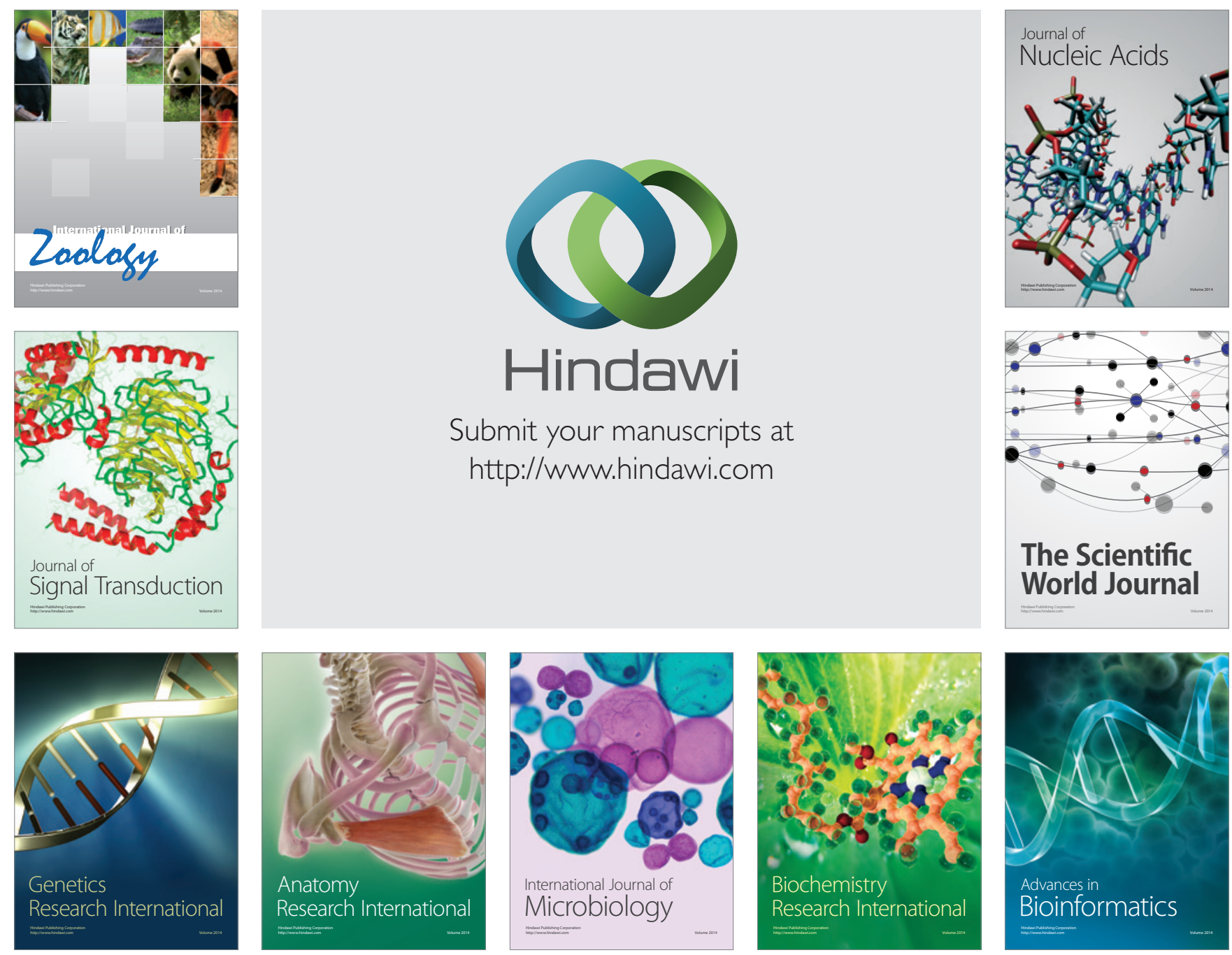

The Scientific World Journal
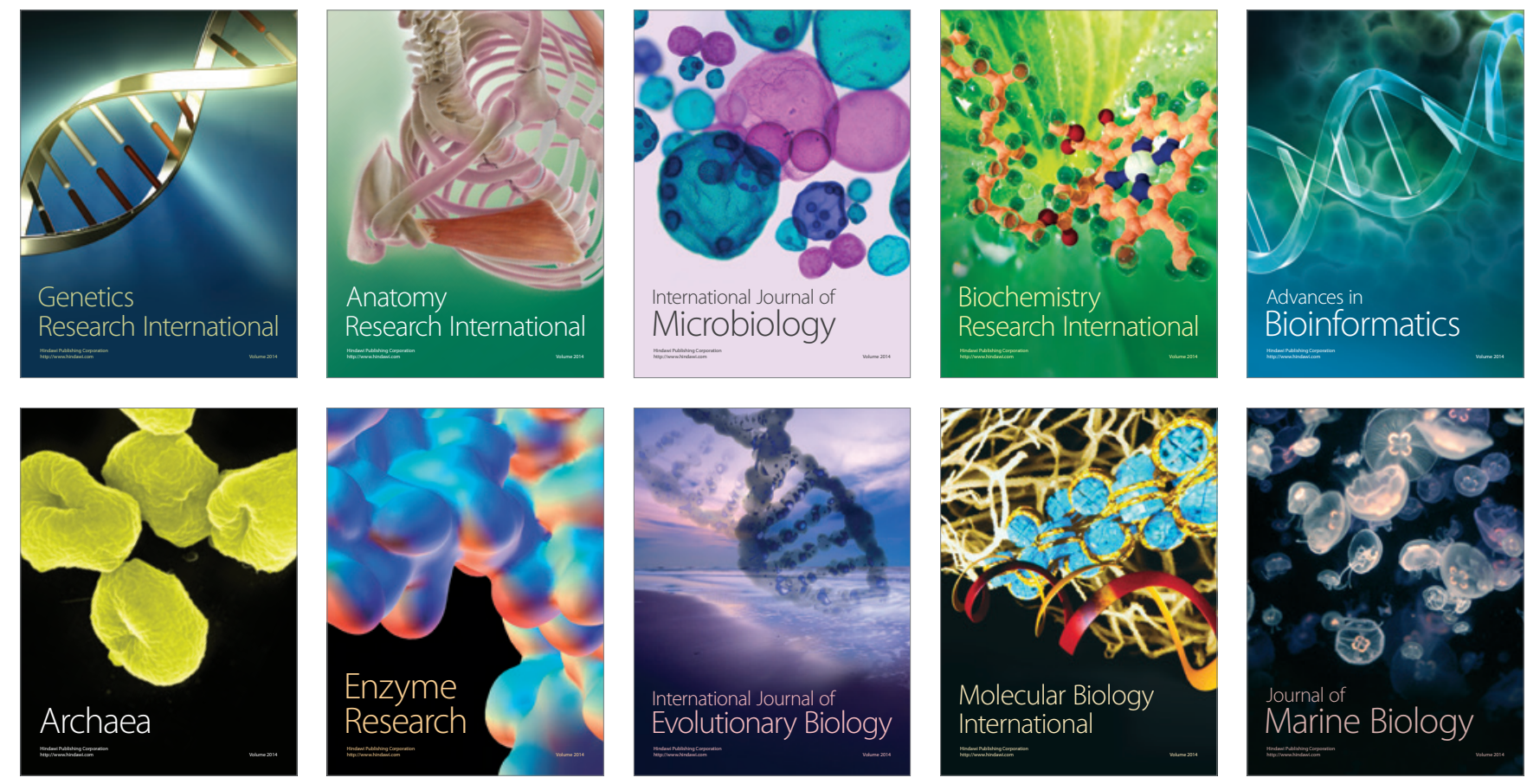